\title{
Model Studies on the Pattern of Volatiles Generated in Mixtures of Amino Acids, Lipid-Oxidation-Derived Aldehydes, and Glucose
}

\author{
An Adams, ${ }^{\dagger}$ Vaida Kitryte, ${ }^{+, \neq}$Rimantas Venskutonis, ${ }^{\ddagger}$ and Norbert De Kimpe ${ }^{*,+}$ \\ ${ }^{\dagger}$ Department of Sustainable Organic Chemistry and Technology, Faculty of Bioscience Engineering, Ghent University, Coupure links \\ 653, B-9000 Ghent, Belgium \\ ${ }^{\ddagger}$ Department of Food Technology, Kaunas University of Technology, Radvilenu pl. 19, Kaunas LT-3028, Lithuania
}

\begin{abstract}
The development of flavor and browning in thermally treated foods results mainly from the Maillard reaction and lipid degradation but also from the interactions between both reaction pathways. To study these interactions, we analyzed the volatile compounds resulting from model reactions of lysine or glycine with aldehydes originating from lipid oxidation [hexanal, $(E)$ 2-hexenal, or $(2 E, 4 E)$-decadienal] in the presence and absence of glucose. The main reaction products identified in these model mixtures were carbonyl compounds, resulting essentially from amino-acid-catalyzed aldol condensation reactions. Several 2-alkylfurans were detected as well. Only a few azaheterocyclic compounds were identified, in particular 5-butyl-2-propylpyridine from $(E)$-2-hexenal model systems and 2-pentylpyridine from $(2 E, 4 E)$-decadienal model reactions. Although few reaction products were found resulting from the condensation of an amino acid with a lipid-derived aldehyde, the amino acid plays an important role in catalyzing the degradation and further reaction of these carbonyl compounds. These results suggest that amino-acidinduced degradations and further reactions of lipid oxidation products may be of considerable importance in thermally processed foods.
\end{abstract}

KEYWORDS: Aroma volatiles, Maillard reaction, lipid oxidation, lysine, glycine, hexanal, (E)-2-hexenal, $(2 E, 4 E)$-decadienal

\section{INTRODUCTION}

Two of the most important reactions responsible for the development of flavor and color in processed foods are lipid degradation, on the one hand, and the Maillard reaction, occurring between a carbohydrate and an amino compound, on the other hand. The interaction between these two reactions has been the subject of several studies, because the course of both reactions can be modified by the reactants, intermediates, and products of the other. 1,2

In this respect, it was recently shown that secondary lipid oxidation products having two oxygenated functions are able to degrade amino acids by a Strecker-type mechanism., ${ }^{3,4}$ This reaction results in the formation of the Strecker aldehyde of the corresponding amino acid and an unsaturated imine, which cyclizes to 2-alkylpyridine (in the case of 4,5-epoxy-2-alkenal) or 2-pentyl-1H-pyrrole (in the case of 4-hydroxy-2-nonenal).

Most studies on the interaction between the Maillard reaction and lipid degradation focused on meat flavor and, thus, the reactions between carbonyl compounds and cysteine or its degradation products, hydrogen sulfide and ammonia. ${ }^{1}$ Studies on the thermal interaction of amino acids with triglycerides reported $\mathrm{N}$-substituted amides and nitriles as the major products, ${ }^{5,6}$ while 2-pentylpyridine was the major product from the reactions of valine with linoleic acid and its esters. ${ }^{7}$ Macku and Shibamoto ${ }^{8}$ investigated the volatile components from heated corn oil with and without glycine. Several nitrogencontaining compounds were formed from these interactions, such as nitriles, pyridines, and pyrroles. As a result of the addition of glycine $(0.5-10 \%)$ to the oil, the amount of released volatiles decreased to almost $50 \%$. Especially because the amount of unsaturated aldehydes decreased (almost 100 times), the authors concluded that secondary reactions occurred between glycine and those aldehydes. Similar compounds were detected in the headspace of soybean oil heated with glycine. In this case, also the addition of cane sugar was investigated, which affected flavor formation. ${ }^{9}$

To identify the origin of several of these volatiles, model reactions were performed using amino acids (lysine and glycine) and long-chain aldehydes with a varying degree of unsaturation, in particular, hexanal, $(E)$-2-hexenal, and $(2 E, 4 E)$-decadienal, known as common lipid oxidation products. ${ }^{10}$ In addition, the influence of the addition of glucose to the model systems on the volatiles produced was studied, as well as the interaction between the different constituents. The high-molecular-weight polycondensation products of the same model reactions have been characterized before by a combination of different analytical methods. These results have been discussed elsewhere. ${ }^{10}$

\section{MATERIALS AND METHODS}

Materials. Glycine (>99\%), L(+)-lysine monohydrochloride (>99\%), and hexanal $(>98 \%)$ were obtained from Sigma-Aldrich (Bornem, Belgium). (2E,4E)-Decadienal (95\%) was obtained from Acros Organics (Geel, Belgium). (E)-2-Hexenal (>99\%) was obtained from Janssen Chimica (Beerse, Belgium). D(+)-Glucose (>99\%, anhydrous) was obtained from Fluka (Bornem, Belgium). Solvents were of analytical

Received: October 19, 2010

Accepted: December 23, 2010

Revised: December 20, 2010

Published: January 25, 2011 
Table 1. Volatile Compounds (Percentage of Total GC Peak Area as Measured by SPME-GC-MS) Identified after Thermal Interaction of Glycine (Gly) or Lysine (Lys) with Hexanal (Hexa) or (E)-2-Hexenal (Hexe) in the Absence and Presence of Glucose

\begin{tabular}{|c|c|c|c|c|c|c|c|c|c|c|c|c|c|c|}
\hline \multirow[b]{2}{*}{ compound } & \multirow[b]{2}{*}{$\begin{array}{l}\mathrm{LRI}^{a} \\
(\exp )\end{array}$} & \multirow[b]{2}{*}{$\begin{array}{l}\text { LRI } \\
\text { (lit) }\end{array}$} & \multicolumn{4}{|c|}{$125^{\circ} \mathrm{C}, 20 \mathrm{~min}$} & \multicolumn{4}{|c|}{$125^{\circ} \mathrm{C}, 120 \mathrm{~min}$} & \multicolumn{4}{|c|}{$125^{\circ} \mathrm{C}, 20 \mathrm{~min},+$ glucose } \\
\hline & & & $\begin{array}{l}\text { Lys } \\
\text { Hexa }\end{array}$ & $\begin{array}{l}\text { Lys } \\
\text { Hexe }\end{array}$ & $\begin{array}{l}\text { Gly } \\
\text { Hexa }\end{array}$ & $\begin{array}{c}\text { Gly } \\
\text { Hexe }\end{array}$ & $\begin{array}{l}\text { Lys } \\
\text { Hexa }\end{array}$ & $\begin{array}{l}\text { Lys } \\
\text { Hexe }\end{array}$ & $\begin{array}{l}\text { Gly } \\
\text { Hexa }\end{array}$ & $\begin{array}{l}\text { Gly } \\
\text { Hexe }\end{array}$ & $\begin{array}{l}\text { Lys } \\
\text { Hexa }\end{array}$ & $\begin{array}{l}\text { Lys } \\
\text { Hexe }\end{array}$ & $\begin{array}{l}\text { Gly } \\
\text { Hexa }\end{array}$ & $\begin{array}{l}\text { Gly } \\
\text { Hexa }\end{array}$ \\
\hline acetaldehyde $^{b}$ & $<600$ & & $-c$ & - & - & - & - & - & - & - & - & 0.64 & - & - \\
\hline ethanol $^{b}$ & $<600$ & & - & 0.30 & - & - & - & - & - & - & - & 0.42 & - & 0.62 \\
\hline 1-pentene ${ }^{d}$ & $<600$ & & - & 1.36 & - & 3.33 & - & 1.17 & - & - & - & 0.53 & - & 0.60 \\
\hline pentane $^{b}$ & $<600$ & & - & - & 3.03 & - & - & - & - & - & 2.73 & - & 1.53 & - \\
\hline acetic acid $^{b}$ & $<600$ & $600^{e}$ & 0.14 & - & - & - & - & - & - & - & - & - & - & - \\
\hline butanal $^{b}$ & $<600$ & $596^{f}$ & 0.02 & 0.71 & - & 0.26 & 0.03 & 0.09 & - & 0.02 & - & 1.46 & - & 1.84 \\
\hline 2-butanone ${ }^{b}$ & 600 & $592^{g}$ & - & - & - & 0.04 & 0.09 & 0.34 & - & 0.24 & - & - & - & - \\
\hline 1-penten-3-ol & 699 & $694^{h}$ & - & 0.18 & - & 0.25 & - & 0.25 & - & 0.10 & - & 0.08 & - & 0.17 \\
\hline 2-pentanone ${ }^{b}$ & 703 & $703^{h}$ & - & 0.31 & - & 0.61 & - & 0.88 & - & 0.96 & - & 0.11 & - & 0.25 \\
\hline pentanal $^{b}$ & 708 & $704^{i}$ & 0.44 & - & 0.15 & - & 0.67 & - & - & - & 0.15 & - & 0.19 & - \\
\hline 1-ethoxy-1-butene ${ }^{d}$ & 709 & & - & - & - & - & - & - & - & - & - & 0.85 & - & 1.44 \\
\hline 2-ethylfuran ${ }^{b}$ & 710 & $702^{i}$ & - & 3.65 & - & 1.41 & - & 6.96 & - & 0.71 & - & 1.44 & - & 2.76 \\
\hline 2-methyl-3-pentanone ${ }^{d}$ & 728 & & - & 0.30 & - & - & - & - & - & - & - & 0.41 & - & 0.73 \\
\hline (E)-2-methyl-2-butenal & 744 & $745^{h}$ & - & 0.36 & - & 0.21 & - & - & - & - & - & - & - & 0.14 \\
\hline 2-ethylbutanal ${ }^{b}$ & 761 & & 0.52 & - & 1.81 & - & 1.32 & 0.15 & 1.49 & - & 1.07 & - & 1.60 & - \\
\hline 3-methylpentanal ${ }^{d}$ & 767 & & 0.08 & - & - & - & - & - & - & - & - & - & - & - \\
\hline 1-pentanol ${ }^{\mathrm{b}}$ & 771 & $772^{g}$ & 1.31 & - & 2.35 & - & 4.71 & - & 2.65 & - & 2.99 & - & 3.30 & - \\
\hline 3-hexanone ${ }^{b}$ & 786 & $788^{g}$ & - & - & 0.68 & - & 0.65 & - & 1.50 & - & 0.45 & - & 0.64 & - \\
\hline 2-hexanone ${ }^{b}$ & 794 & $792^{g}$ & 0.17 & - & 0.80 & 0.24 & 0.67 & 1.07 & 2.62 & 1.19 & 0.41 & - & 0.60 & - \\
\hline hexanal $^{b}$ & 801 & $800^{i}$ & 78.28 & 4.32 & 4.98 & 0.22 & 22.72 & - & 0.61 & - & 27.24 & 14.92 & 31.59 & 13.43 \\
\hline ethyl butanoate ${ }^{b}$ & 804 & $804^{i}$ & - & 0.26 & - & - & - & 0.56 & - & 0.37 & - & 0.22 & - & 0.36 \\
\hline 2-ethyl-2(E)-butenal ${ }^{b}$ & 817 & & - & 2.94 & - & 6.27 & - & 0.40 & - & 0.27 & - & 2.27 & - & 4.37 \\
\hline pentyl formate $^{d}$ & 828 & & - & - & - & - & 0.92 & - & - & - & 0.98 & - & 0.20 & - \\
\hline$(E)-2$-hexenal ${ }^{b}$ & 851 & $846^{i}$ & - & 0.20 & - & - & - & - & - & - & - & 35.34 & - & 1.87 \\
\hline ethylbenzene & 857 & $864^{j}$ & - & 0.14 & - & - & - & 0.42 & - & 0.39 & - & 0.15 & - & 0.23 \\
\hline 2-methylhexanal ${ }^{d}$ & 860 & & - & - & 0.11 & - & - & - & 0.17 & - & - & - & 0.13 & - \\
\hline 2-methylenehexanal ${ }^{d}$ & 861 & & - & - & 0.36 & - & - & - & - & - & - & - & 1.12 & 0.19 \\
\hline$(Z)$-2-hexenol ${ }^{b}$ & 866 & $859^{i}$ & - & 0.96 & - & - & - & 2.10 & - & 2.93 & - & 0.45 & - & 1.79 \\
\hline 3-heptanone & 886 & $888^{h}$ & - & 0.57 & - & 0.41 & - & 1.90 & - & 1.81 & - & 0.36 & - & 0.78 \\
\hline pentanoic acid & 894 & $904^{k}$ & - & - & - & - & 0.42 & - & - & - & - & - & 0.36 & - \\
\hline nonane $^{b}$ & 899 & 900 & 0.25 & - & 0.16 & - & - & - & 0.35 & - & 0.13 & - & 0.41 & - \\
\hline propyl butanoate & 900 & $896^{i}$ & - & 0.15 & - & - & - & 0.51 & - & 0.38 & - & 0.12 & - & 0.25 \\
\hline ethyl pentanoate ${ }^{b}$ & 903 & $898^{i}$ & - & 0.10 & - & - & - & 0.22 & - & 0.18 & - & 0.08 & - & 0.18 \\
\hline 1,1-diethoxybutane ${ }^{b}$ & 905 & & - & 16.82 & - & - & - & 38.34 & - & 45.69 & - & 11.17 & - & 20.87 \\
\hline 2-butylfuran ${ }^{b}$ & 909 & $893^{h}$ & - & - & - & - & - & - & - & - & - & - & 0.10 & - \\
\hline 2-methyl-2-cyclopenten-1-one ${ }^{b}$ & 912 & $912^{h}$ & - & - & - & - & - & 0.55 & - & 0.05 & - & 0.18 & - & 0.16 \\
\hline methyl hexanoate $^{b}$ & 925 & $916^{f}$ & - & - & 0.16 & - & - & - & 3.47 & - & - & - & - & - \\
\hline 2-ethyl-2-pentenal ${ }^{d}$ & 929 & & - & 0.74 & - & 1.17 & - & 0.37 & - & 0.16 & - & - & - & 0.28 \\
\hline 3-methyl-4-heptanone ${ }^{d}$ & 930 & & - & - & - & - & - & 0.19 & - & 0.23 & - & - & - & - \\
\hline 3-ethyl-2-methyl-1,3-hexadiene ${ }^{d}$ & 948 & & - & - & - & 0.33 & - & 2.28 & - & 2.21 & - & - & - & 0.58 \\
\hline 2-ethylhexanal & 953 & $956^{j}$ & - & 0.13 & - & 0.29 & - & 0.46 & - & - & - & - & - & - \\
\hline hexanoic acid ${ }^{b}$ & 983 & $967^{i}$ & 12.01 & - & 0.17 & - & 15.89 & - & - & - & 14.91 & - & 8.41 & - \\
\hline 2-ethyl-2(Z)-hexenal ${ }^{d}$ & 999 & & - & 3.55 & - & 26.38 & - & 4.63 & - & 2.75 & - & 0.57 & - & 1.29 \\
\hline decane $^{b}$ & 1001 & 1000 & - & - & - & - & 1.53 & - & - & - & 1.32 & - & - & - \\
\hline 2-ethyl-2(E)-hexenal ${ }^{b}$ & 1006 & & - & 4.12 & - & 5.39 & - & 0.70 & - & 0.11 & - & 0.34 & - & 0.86 \\
\hline 2-hexen-1-yl acetate & 1017 & $1010^{i}$ & - & 1.37 & - & - & - & 2.25 & - & 2.05 & - & - & - & 1.44 \\
\hline 5-ethyl-2(5H)-furanone ${ }^{d}$ & 1037 & & - & 0.14 & - & - & - & - & - & - & - & - & - & - \\
\hline butylbenzene & 1056 & $1067^{g}$ & - & - & - & - & - & 0.59 & - & 0.48 & - & - & - & - \\
\hline (E)-2-octenal ${ }^{b}$ & 1057 & $1057^{f}$ & - & 0.10 & - & - & - & - & - & - & - & - & - & - \\
\hline
\end{tabular}


Table 1. Continued

\begin{tabular}{|c|c|c|c|c|c|c|c|c|c|c|c|c|c|c|}
\hline \multirow[b]{2}{*}{ compound } & \multirow[b]{2}{*}{$\begin{array}{l}\mathrm{LRI}^{a} \\
(\exp )\end{array}$} & \multirow[b]{2}{*}{$\begin{array}{l}\text { LRI } \\
\text { (lit) }\end{array}$} & \multicolumn{4}{|c|}{$125^{\circ} \mathrm{C}, 20 \mathrm{~min}$} & \multicolumn{4}{|c|}{$125^{\circ} \mathrm{C}, 120 \mathrm{~min}$} & \multicolumn{4}{|c|}{$125^{\circ} \mathrm{C}, 20 \mathrm{~min},+$ glucose } \\
\hline & & & $\begin{array}{l}\text { Lys } \\
\text { Hexa }\end{array}$ & $\begin{array}{l}\text { Lys } \\
\text { Hexe }\end{array}$ & $\begin{array}{c}\text { Gly } \\
\text { Hexa }\end{array}$ & $\begin{array}{l}\text { Gly } \\
\text { Hexe }\end{array}$ & $\begin{array}{l}\text { Lys } \\
\text { Hexa }\end{array}$ & $\begin{array}{l}\text { Lys } \\
\text { Hexe }\end{array}$ & $\begin{array}{l}\text { Gly } \\
\text { Hexa }\end{array}$ & $\begin{array}{c}\text { Gly } \\
\text { Hexe }\end{array}$ & $\begin{array}{l}\text { Lys } \\
\text { Hexa }\end{array}$ & $\begin{array}{l}\text { Lys } \\
\text { Hexe }\end{array}$ & $\begin{array}{c}\text { Gly } \\
\text { Hexa }\end{array}$ & $\begin{array}{l}\text { Gly } \\
\text { Hexa }\end{array}$ \\
\hline 4-propyl-1,3-benzenediol ${ }^{d}$ & 1080 & & - & 1.59 & - & 0.35 & - & 2.02 & - & - & - & 0.15 & - & 0.18 \\
\hline 2-butyl-2-pentenal ${ }^{d}$ & 1085 & & - & 0.87 & - & 2.12 & - & - & - & - & - & - & - & - \\
\hline 4-undecene ${ }^{d}$ & 1090 & & 0.12 & - & 0.52 & - & 4.34 & - & 1.39 & - & 0.16 & - & 2.34 & - \\
\hline 5-undecene & 1091 & $1094^{l}$ & 0.16 & - & 0.69 & - & 5.71 & - & 1.83 & - & 0.21 & - & 3.15 & - \\
\hline undecane $^{b}$ & 1101 & 1100 & - & - & - & - & - & - & 1.51 & - & - & - & - & - \\
\hline ethylbenzaldehyde & 1165 & $1171^{m}$ & - & - & - & - & - & - & - & - & - & - & - & 0.14 \\
\hline 5-decanone ${ }^{d}$ & 1176 & & - & - & - & - & 0.37 & - & - & - & - & - & - & - \\
\hline 2-butyl-2-hexenal ${ }^{d}$ & 1178 & & - & 4.03 & - & 8.83 & - & 2.69 & - & 0.43 & - & 0.18 & - & 0.97 \\
\hline 5-undecanone ${ }^{d}$ & 1276 & & - & - & - & - & 3.83 & - & 1.78 & - & - & - & - & - \\
\hline 4-ethyl-(2E,4E,6E)-decatrienal ${ }^{d}$ & 1361 & & - & 11.69 & - & 6.31 & - & 4.18 & - & 1.17 & - & 5.89 & - & 10.59 \\
\hline (Z)-2-butyl-2-octenal ${ }^{b}$ & 1374 & $1378^{n}$ & 3.35 & 3.78 & 78.08 & 3.23 & 24.78 & 2.38 & 56.38 & 0.21 & 38.53 & 0.41 & 37.10 & 1.31 \\
\hline (E)-2-butyl-2-octenal ${ }^{b}$ & 1388 & $1385^{\circ}$ & 0.26 & 0.15 & 4.07 & 0.04 & 0.48 & - & 1.68 & - & 2.73 & - & 6.08 & - \\
\hline 4-ethyl-(2E,4Z,6E)-decatrienal ${ }^{d}$ & 1398 & & - & - & - & - & - & - & - & - & - & 1.73 & - & 3.32 \\
\hline 5-butyl-2-propylpyridine ${ }^{d}$ & 1400 & & - & - & - & - & - & 2.28 & - & 2.83 & - & - & - & - \\
\hline total GC peak area $\left(\times 10^{8}\right)$ & & & 5.58 & 4.32 & 3.55 & 2.80 & 2.32 & 2.06 & 2.13 & 1.77 & 2.69 & 2.86 & 2.43 & 2.71 \\
\hline unidentified (\%) & & & 2.89 & 34.11 & 1.88 & 32.31 & 10.87 & 19.07 & 22.57 & 32.08 & 5.99 & 19.53 & 1.15 & 26.01 \\
\hline
\end{tabular}

${ }^{a}$ Comparison of calculated (calc) linear retention index (LRI) on the AT-5MS stationary phase to literature data (lit). ${ }^{b}$ Identification confirmed by a comparison to the authentic reference substance. ${ }^{c}$ Not detected. ${ }^{d}$ Tentatively identified. ${ }^{e}$ From ref $27 .{ }^{f}$ From ref $28 .{ }^{g}$ From ref $8 .{ }^{h}$ From ref $29 .{ }^{i}$ From ref $30 .{ }^{j}$ From ref $32 .{ }^{k}$ From ref $33 .{ }^{l}$ From ref $10 .{ }^{m}$ From ref $34 .{ }^{n}$ From ref $31 .{ }^{o}$ From ref 35.

grade. All standards used for compound identification were of high purity ( $>95 \%$ ), with 2,5-dimethylfuran, 2-acetylfuran, (E)-2-hexenol, (E)-2-hexenoic acid, (E)-2-octenal, heptanal, and methyl hexanoate from Sigma-Aldrich, crotonaldehyde, valeraldehyde, benzaldehyde, (E)-2-heptenal, (E)-2-decenal, 1-butanol, 1-pentanol, 1,1-diethoxybutane, 2-butanone, 2-pentanone, 2-hexanone, 3-hexanone, 2-methyl2-cyclopenten-1-one, 2-methylfuran, and 2-ethylfuran from Acros Organics, butyraldehyde and hexanoic acid from Janssen Chimica, acetaldehyde, 2-heptanone, 2-furaldehyde, ethyl butyrate, and ethyl valerate from Fluka, 2-ethylcrotonaldehyde, 2-ethylbutyraldehyde, and 2-ethyl-2-hexenal (mixture of $E / Z$ isomers) from TCI Europe (Zwijndrecht, Belgium), and 2-propylfuran, 2-butylfuran, 2-pentylfuran, and 2-hexylfuran (97\%) from Alfa Aesar (Karlsruhe, Germany).

Model Reactions. For this purpose, $5 \mathrm{mmol}$ of amino acid and 2.5 mmol of aldehyde [hexanal or $(E)$-2-hexenal] with or without $5 \mathrm{mmol}$ of $\mathrm{D}(+)$-glucose were well-mixed in a $20 \mathrm{~mL}$ solid-phase microextraction (SPME) vial, covered with a magnetic crimp cap with a septum (natural rubber red orange/Teflon; $55^{\circ}$ Shore A; $1.3 \mathrm{~mm}$, Supelco, Bornem, Belgium) and placed in an oven (equipped with a fan, Memmert, Schwabach, Germany), which had been preheated to and stabilized at $125^{\circ} \mathrm{C}$. Because of the high reactivity of $(2 E, 4 E)$-decadienal-containing model mixtures, twice lower amounts of initial reactants were used. The amino acid/carbonyl compound mixtures were heated for exactly 20 or $120 \mathrm{~min}$. After heating, the vials with brown-colored reaction products were removed from the oven and placed in a desiccator to cool to room temperature. Most model reactions were performed in duplicate (Table 1), while $(2 E, 4 E)$-decadienal-containing model reactions were performed in triplicate (Table 2).

Synthesis of 2-Butyl-2-octenal. 2-Butyl-2-octenal was prepared as follows. A three-neck flask $(50 \mathrm{~mL})$ was fitted with a sealed stirrer, an efficient reflux condenser, and a dropping funnel containing freshly redistilled hexanal $(30 \mathrm{mmol})$. A NaOH solution $(1 \mathrm{M}, 10 \mathrm{~mL})$ was placed in the flask and heated to $80{ }^{\circ} \mathrm{C}$. The aldehyde was added rapidly under vigorous stirring, after which the reaction mixture was refluxed for $1 \mathrm{~h}$. After cooling to room temperature, the organic layer was extracted with diethylether and dried with $\mathrm{MgSO}_{4}$. After evaporation of the solvent, the $E / Z$ isomer mixture of 2-butyl-2-octenal was obtained in $67 \%$ yield. The gas chromatography (GC) $(E / Z, 4: 96$; linear retention index (LRI, AT5-MS), 1384:1370), mass spectrometry (MS), and nuclear magnetic resonance (NMR) data correspond well with the literature, as reported by Robert et al. ${ }^{12}$

SPME extraction $(5 \mathrm{~min})$ and desorption $(2 \mathrm{~min})$ were performed automatically by means of a MPS-2 autosampler (Gerstel, Mülheim an der Ruhr, Germany). A divinylbenzene/Carboxen/polydimethylsiloxane (DVB/Carboxen/PDMS) fiber (Supelco) was used.

Gas Chromatography-Mass Spectrometry (GC-MS). For the analysis of the SPME extracts, a Hewlett-Packard 6890 GC Plus coupled with a HP 5973 mass selective detector (MSD-quadrupole type), equipped with a CIS-4 programmed temperature vaporization (PTV) injector (Gerstel) and an AT5-MS capillary column $(30 \times 0.25$ $\mathrm{mm}$ inner diameter; coating thickness of $0.25 \mu \mathrm{m}$ ) was used. Working conditions were as follows: injector, $250{ }^{\circ} \mathrm{C}$; transfer line to MSD, $260^{\circ} \mathrm{C}$; oven temperature, start at $40^{\circ} \mathrm{C}$, hold for $2 \mathrm{~min}$, programmed from 40 to $120^{\circ} \mathrm{C}$ at $4{ }^{\circ} \mathrm{C} \mathrm{min}{ }^{-1}$, programmed from 120 to $240{ }^{\circ} \mathrm{C}$ at $30^{\circ} \mathrm{C} \mathrm{m^{-1 }}$, and hold for $2 \mathrm{~min}$; split ratio, 20:1; carrier gas (He),

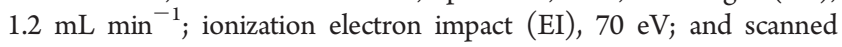
acquisition parameters, $\mathrm{m} / z 40-200(0-10 \mathrm{~min}), \mathrm{m} / z$ 40-300 (10-20 $\mathrm{min}$ ), and $\mathrm{m} / z 40-400$ (>20 $\mathrm{min}$ ). Volatile substances were identified by a comparison of their mass spectra and retention times to those of reference substances and a comparison to the Wiley (6th edition) and National Institute of Standards and Technology (NIST) Mass Spectral Library (version 1.6d) and particular literature data, if available. When only MS data were available, identifications were indicated as tentative.

\section{RESULTS AND DISCUSSION}

The volatiles detected in the headspace of heated model mixtures of lysine or glycine with hexanal, $(E)$-2-hexenal, or $(2 E, 4 E)$-decadienal $(2: 1)$ were investigated in the presence and absence of glucose. The model mixtures were heated in closed vials at $125^{\circ} \mathrm{C}$ for $20 \mathrm{~min}$. In the absence of glucose, a high amount of starting material remained, and therefore, the amino 
Table 2. Volatile Compounds (Percentage of Total GC Peak Area as Measured by SPME-GC-MS) after Heating $\left(125^{\circ} \mathrm{C}\right)$ of Glycine (Gly) or Lysine (Lys) with (2E,4E)-Decadienal (Dcdnl) in the Absence and Presence of Glucose

\begin{tabular}{|c|c|c|c|c|c|c|c|c|c|c|}
\hline \multirow[b]{2}{*}{ compound } & \multirow{2}{*}{$\begin{array}{l}\mathrm{LRI}^{a} \\
(\text { calc) }\end{array}$} & \multirow{2}{*}{$\begin{array}{l}\text { LRI } \\
\text { (lit) }\end{array}$} & \multicolumn{2}{|c|}{$125^{\circ} \mathrm{C}, 20 \mathrm{~min}$} & \multicolumn{2}{|c|}{$125^{\circ} \mathrm{C}, 120 \mathrm{~min}$} & \multicolumn{2}{|c|}{$125^{\circ} \mathrm{C}, 20 \mathrm{~min},+$ glucose } & \multicolumn{2}{|c|}{$125^{\circ} \mathrm{C}, 120 \mathrm{~min},+$ glucos } \\
\hline & & & Lys/Dcdnl & Gly/Dcdnl & Lys/Dcdnl & Gly/Dcdnl & Lys/Dcdnl & Gly/Dcdnl & Lys/Dcdnl & Gly/Dcdnl \\
\hline acetaldehyde $^{b}$ & $<600$ & & 0.34 & 1.79 & 0.72 & 1.38 & 0.73 & 1.01 & 1.04 & 0.58 \\
\hline ethanol $^{b}$ & $<600$ & & 0.52 & 2.28 & 3.32 & 3.92 & 1.20 & 1.15 & 4.75 & 1.53 \\
\hline pentane $^{b}$ & $<600$ & & 0.23 & 1.07 & 1.18 & 1.73 & 0.79 & 0.94 & 3.18 & 0.83 \\
\hline ethyl formate ${ }^{c}$ & $<600$ & & $\mathrm{ta}^{d}$ & 0.35 & 0.23 & $e^{e}$ & 0.60 & 0.48 & 2.38 & 0.61 \\
\hline methyl acetate $^{c}$ & $<600$ & & - & - & - & 4.33 & - & - & - & - \\
\hline butanal $^{b}$ & $<600$ & $596^{f}$ & $\operatorname{ta}^{d}$ & $\operatorname{ta}^{d}$ & 0.17 & 0.54 & - & - & - & 2.22 \\
\hline acetic $\operatorname{acid}^{b}$ & 602 & $610^{g}$ & - & - & - & - & 0.45 & - & 1.04 & 1.21 \\
\hline 2-methylfuran ${ }^{b}$ & 603 & $612^{g}$ & - & - & - & - & - & - & 1.32 & - \\
\hline ethyl acetate ${ }^{b}$ & 611 & $606^{h}$ & - & - & - & - & - & - & 1.47 & - \\
\hline 2-butenal ${ }^{b}(E / Z)$ & 650 & $651^{g}$ & 0.21 & 0.19 & 0.14 & - & - & - & - & - \\
\hline 1-butanol ${ }^{b}$ & 660 & & - & - & 0.14 & 0.10 & $\operatorname{ta}^{d}$ & $\operatorname{ta}^{d}$ & - & 0.20 \\
\hline 1-heptene & 687 & $694^{i}$ & $\operatorname{ta}^{d}$ & 0.25 & 3.26 & 0.70 & 0.19 & 0.68 & 2.51 & 4.50 \\
\hline pentanal $^{b}$ & 699 & $704^{h}$ & 0.49 & 2.66 & 1.21 & 1.00 & 0.91 & - & 0.55 & 1.15 \\
\hline 2,5-dimethylfuran ${ }^{b}$ & 710 & $711^{g}$ & - & - & - & - & - & - & 0.20 & $\operatorname{ta}^{d}$ \\
\hline 1-methyl-1H-pyrrole & 732 & $750^{i}$ & - & $\operatorname{ta}^{d}$ & - & $\operatorname{ta}^{d}$ & - & - & - & - \\
\hline toluene $^{b}$ & 760 & & 4.46 & 33.15 & 29.41 & 36.55 & 15.26 & 9.84 & 27.30 & 6.89 \\
\hline 1-pentanol ${ }^{b}$ & 765 & $772^{i}$ & 0.12 & 1.08 & 1.32 & 1.82 & 0.67 & 0.30 & 1.30 & 0.48 \\
\hline 2-hexanone ${ }^{b}$ & 788 & $792^{i}$ & $\mathrm{ta}^{d}$ & 0.19 & 1.26 & 1.53 & $\mathrm{ta}^{d}$ & - & 0.56 & 0.54 \\
\hline hexanal $^{b}$ & 800 & $800^{h}$ & 7.33 & 17.16 & 11.81 & 4.52 & 34.53 & 12.36 & 6.39 & 28.20 \\
\hline 2-ethyl-2(E)-butenal ${ }^{b}$ & 817 & & - & - & - & 0.11 & - & - & - & - \\
\hline methyl pentanoate & 822 & $821^{h}$ & - & - & - & 0.90 & - & - & - & - \\
\hline 1,3-octadiene ${ }^{c}$ & 823 & & - & - & - & - & - & - & - & 12.45 \\
\hline furfural $^{b}$ & 833 & $830^{h}$ & - & - & - & - & - & 0.29 & - & - \\
\hline ethylbenzene & 856 & $860^{j}$ & $\operatorname{ta}^{d}$ & 0.46 & 0.36 & 0.47 & 0.28 & 0.13 & 0.45 & 0.37 \\
\hline 1,3-dimethylbenzene ${ }^{c}$ & 866 & & $\operatorname{ta}^{d}$ & 0.31 & 0.33 & 0.18 & 0.18 & 0.11 & 0.31 & 0.30 \\
\hline 2-heptanone ${ }^{b}$ & 889 & $893^{i}$ & - & 0.82 & - & 2.33 & - & - & - & - \\
\hline 2-butylfuran ${ }^{b}$ & 889 & & 0.32 & - & 3.20 & - & 0.65 & 0.24 & 2.32 & 1.90 \\
\hline 3(E)-nonene ${ }^{b}$ & 897 & $900^{j}$ & $\operatorname{ta}^{d}$ & 0.36 & 0.54 & 0.50 & 0.14 & $\operatorname{ta}^{d}$ & 0.27 & $\operatorname{ta}^{d}$ \\
\hline heptanal $^{b}$ & 902 & $908^{k}$ & 0.15 & 0.76 & 0.39 & 0.45 & 0.81 & 0.50 & 0.59 & 1.23 \\
\hline 2-acetylfuran ${ }^{b}$ & 912 & $912^{g}$ & - & - & - & - & - & - & 0.36 & 0.21 \\
\hline 1,2 -nonadiene ${ }^{c}$ & 924 & & 0.21 & 1.99 & 2.16 & 6.40 & 0.36 & 0.34 & 4.82 & 1.10 \\
\hline $2(E)$-heptenal $^{b}$ & 956 & $947^{h}$ & $\mathrm{ta}^{d}$ & - & - & - & 0.10 & - & - & - \\
\hline benzaldehyde ${ }^{b}$ & 959 & $952^{h}$ & 6.12 & 5.96 & 5.97 & 0.51 & 4.91 & 7.26 & 0.25 & 8.23 \\
\hline 2-pentylfuran ${ }^{b}$ & 989 & $993^{k}$ & 0.68 & 0.18 & 3.23 & 0.20 & 0.65 & 0.28 & 2.41 & 0.61 \\
\hline 2-ethyl-2(E)-hexenal ${ }^{b}$ & 1004 & & 0.22 & 0.64 & 1.25 & 0.61 & 0.69 & - & 0.56 & - \\
\hline octanal & 1004 & $998^{h}$ & - & - & - & - & - & $\operatorname{ta}^{d}$ & - & 0.23 \\
\hline butylbenzene & 1053 & $1067^{i}$ & 0.22 & 0.33 & 2.61 & 0.94 & 0.44 & 0.13 & 1.93 & 0.77 \\
\hline $2(E)$-octenal $^{b}$ & 1058 & $1049^{h}$ & 0.58 & - & - & - & 2.33 & 0.33 & - & - \\
\hline 2,4-decadienol ${ }^{c}$ & 1083 & & - & - & 0.22 & - & - & - & 0.10 & - \\
\hline 2-hexylfuran ${ }^{b}$ & 1089 & & 0.18 & - & 0.47 & - & - & - & 0.45 & 0.18 \\
\hline 1,1-diethoxyethane ${ }^{c}$ & 1090 & & - & 0.37 & - & 0.57 & 0.27 & 0.10 & - & - \\
\hline 4-undecene ${ }^{c}$ & 1091 & & - & - & 0.21 & - & - & - & 0.21 & 0.14 \\
\hline 5-undecene & 1093 & $1094^{j}$ & - & - & 0.21 & - & - & - & 0.21 & 0.14 \\
\hline 2-hex-1-enylfuran ${ }^{c}(E / Z)$ & 1135 & & $\operatorname{ta}^{d}$ & - & 0.10 & - & $\operatorname{ta}^{d}$ & - & 0.22 & - \\
\hline pentylbenzene & 1154 & $1152^{j}$ & - & $\operatorname{ta}^{d}$ & - & 0.10 & - & - & - & $\operatorname{ta}^{d}$ \\
\hline 2-hex-1-enylfuran ${ }^{c}(E / Z)$ & 1157 & & 0.19 & - & 0.61 & - & 0.12 & - & 0.66 & - \\
\hline 1,3,5-undecatriene & 1184 & $1183^{j}$ & - & 0.17 & - & $\mathrm{ta}^{d}$ & - & - & - & - \\
\hline $4(Z)$-decenal & 1195 & $1193^{h}$ & 9.53 & - & - & - & 5.23 & 7.62 & 2.05 & 2.66 \\
\hline 2-pentylpyridine & 1196 & $1205^{i}$ & - & 1.04 & 0.53 & 0.62 & - & - & - & - \\
\hline decanal & 1205 & $1201^{h}$ & 0.12 & - & - & - & - & - & 0.20 & - \\
\hline
\end{tabular}


Table 2. Continued

\begin{tabular}{|c|c|c|c|c|c|c|c|c|c|c|}
\hline \multirow[b]{2}{*}{ compound } & \multirow[b]{2}{*}{$\begin{array}{l}\mathrm{LRI}^{a} \\
\text { (calc) }\end{array}$} & \multirow[b]{2}{*}{$\begin{array}{l}\text { LRI } \\
\text { (lit) }\end{array}$} & \multicolumn{2}{|c|}{$125^{\circ} \mathrm{C}, 20 \mathrm{~min}$} & \multicolumn{2}{|c|}{$125^{\circ} \mathrm{C}, 120 \mathrm{~min}$} & \multicolumn{2}{|c|}{$125^{\circ} \mathrm{C}, 20 \mathrm{~min},+$ glucose } & \multicolumn{2}{|c|}{$125^{\circ} \mathrm{C}, 120 \mathrm{~min},+$ glucos } \\
\hline & & & Lys/Dcdnl & Gly/Dcdnl & Lys/Dcdnl & Gly/Dcdnl & Lys/Dcdnl & Gly/Dcdnl & Lys/Dcdnl & Gly/Dcdnl \\
\hline $2(E)$-decenal ${ }^{b}$ & 1261 & $1260^{h}$ & 0.33 & - & - & - & 0.23 & 0.33 & - & - \\
\hline 2-pentyl-2-cyclopentene-1-one & 1263 & $1288^{h}$ & - & 0.26 & - & 2.28 & - & - & - & - \\
\hline$(2 E, 4 Z)$-decadienal & 1293 & $1292^{h}$ & 6.93 & - & - & - & 2.71 & 5.71 & - & - \\
\hline$(2 E, 4 E)$-decadienal $l^{b}$ & 1320 & $1319^{h}$ & 54.85 & 0.63 & 0.13 & 0.19 & 18.68 & 40.37 & - & - \\
\hline 2,4-decadienal $(Z, E / Z)^{c}$ & 1325 & & - & 0.72 & 0.28 & 0.33 & 0.33 & 0.50 & - & - \\
\hline 2,6-dodecadienal ${ }^{c}(E / Z)$ & 1334 & & 0.42 & 1.68 & 1.83 & 1.23 & 0.13 & 0.64 & 2.21 & 2.28 \\
\hline 2,6-dodecadienal ${ }^{c}(E / Z)$ & 1335 & & 0.32 & 1.44 & 2.36 & 1.79 & 0.11 & 0.48 & 2.87 & 2.65 \\
\hline 2,6-dodecadienal ${ }^{c}(E / Z)$ & 1354 & & 2.75 & 11.05 & 10.64 & 9.24 & 0.65 & 3.92 & 14.89 & 11.21 \\
\hline 2-butyl-2(Z)-octenal ${ }^{g}$ & 1370 & & - & $\mathrm{ta}^{d}$ & $\mathrm{ta}^{d}$ & $\operatorname{ta}^{d}$ & - & - & $\mathrm{ta}^{d}$ & - \\
\hline total GC peak area $\left(\times 10^{8}\right)$ & & & 7.29 & 2.65 & 2.73 & 2.41 & 5.51 & 5.09 & 3.10 & 2.56 \\
\hline unidentified (\%) & & & 2.18 & 10.66 & 8.2 & 11.93 & 4.79 & 3.96 & 7.67 & 4.4 \\
\hline
\end{tabular}

${ }^{a}$ Comparison of calculated (calc) linear retention index (LRI) on the AT-5MS stationary phase to literature data (lit). ${ }^{b}$ Identification confirmed by a comparison to the authentic reference substance. ${ }^{c}$ Tentatively identified. ${ }^{d}$ Trace amounts $(<0.1 \%) .{ }^{e}$ Not detected. ${ }^{f}$ From ref $28 .{ }^{g}$ From ref 36. ${ }^{h}$ From ref $30 .{ }^{i}$ From ref $8 .{ }^{j}$ From ref $10 .{ }^{k}$ From ref 29.

acid/lipid oxidation product model mixtures were also heated for $120 \mathrm{~min}$. After cooling to room temperature, the headspace of the heated vials was directly analyzed by means of SPME-GC-MS. The volatiles identified in the different model reactions are presented in Tables 1 and 2 . The results are mean values of two (Table 1) or three (Table 2) replicated experiments. Concerning the variability on the results obtained, the relative standard deviation ranges from 0 to $110 \%$. The high standard deviations were noted for compounds present in low amounts. For the most important compounds (abundance >5\%), the relative standard deviation usually remained lower than $10 \%$, apart from a few exceptions (such as hexanoic acid, which gives an irregular chromatographic peak).

The amounts of volatiles detected in the headspace of amino acid/lipid oxidation product mixtures heated at $125^{\circ} \mathrm{C}$ for 120 min (total GC peak area of around $1.8-2.3 \times 10^{8}$ ) were lower than for the mixtures heated at the same temperature for a shorter time of $20 \mathrm{~min}$ (total GC peak area of $2.8-5.6 \times 10^{8}$ ). This was mainly due to the decrease of the volatile starting material hexanal with longer heating times. In the lysine/hexanal model system, for example, $78.3 \%$ of the total GC peak area was due to hexanal remaining after $20 \mathrm{~min}$ of reaction. After $120 \mathrm{~min}$ of reaction time, this percentage had decreased to $22.7 \%$. Much lower amounts of (E)-2-hexenal remained after heating (Table 1). This can be explained by the $\alpha, \beta$ unsaturation of the carbonyl group, which makes $(E)$-2-hexenal more reactive. Only in the presence of glucose, a relatively high amount of $(E)$ 2-hexenal remained unreacted after heating, especially in the lysine/(E)-2-hexenal/glucose model mixture (35.3\%), indicating that lysine reacts preferably with glucose or its degradation products, as compared to (E)-2-hexenal. In the case of $(2 E, 4 E)$-decadienal, considerable amounts of unreacted starting material were found in lysine model systems heated for $20 \mathrm{~min}$ (54.9\%). Upon prolonged heating, most of the starting material disappeared (Table 1).

As the prepared reaction mixtures were heated in hermetically closed vials, a decreasing amount of low-molecular volatiles results from reactions incorporating low-molecular-weight volatiles into nonvolatile reaction products and, eventually, in the skeleton of the final colored polycondensation reaction products.
Results on the formation and characterization of these polycondensation products of high molecular weight have been discussed elsewhere. $^{10}$

The most important part of the volatiles identified were carbonyl compounds, resulting from the starting aldehydes and aldol condensation reactions thereof. The hexanal aldol condensation products $(Z)$-2-butyl-2-octenal and (E)-2-butyl-2-octenal dominated in the headspace of most hexanal-containing heated samples (Table 1). The identification and elution order of both isomers was established based on the synthesized reference compounds. ${ }^{12}$ For (Z)-2-butyl-2-octenal, a low odor threshold $(20 \mu \mathrm{g} / \mathrm{L}$ water $)$ and an attractive ham-like, meaty, savory odor have been reported. ${ }^{12}$

These aldol condensation products were not detected when hexanal was heated alone. Hence, the aldol condensation reaction of this aldehyde is strongly catalyzed by the presence of an amino acid. It has been reported in the literature that amino acids as well as small peptides can catalyze aldol reactions. ${ }^{13-15}$ To explain the stereoselectivity obtained in specific cases, a mechanism was proposed in which the ketone donor reacts with the amino acid with the formation of an enamine. Afterward, the acceptor aldehyde reacts with the chiral enamine and, upon hydrolysis, an enantiomerically enriched aldol product can be generated. ${ }^{15}$ In the case of the basic amino acids lysine and arginine (when unprotonated), however, reported yields were low and no diastereoselectivity was obtained, indicating that only a general base aldolization mechanism took place in these cases. ${ }^{16}$ The conversion of hexanal to 2-butyl-2-octenal in our study occurred much more readily in the presence of glycine than in the presence of lysine, which can be explained by the lower nucleophilicity of the primary amino group of lysine monohydrochloride $\left(\mathrm{p} K_{\mathrm{a}}=8.95\right)$, as compared to glycine $\left(\mathrm{p} K_{\mathrm{a}}=9.78\right)$. Thus, after $20 \mathrm{~min}$ of reaction, lysine/hexanal model mixtures contained $78.3 \%$ hexanal and only 3.6\% 2-butyl-2-octenal, while glycine/ hexanal model mixtures contained $5.0 \%$ hexanal and $82.2 \%$ of the aldol product, 2-butyl-2-octenal (sum of $E$ and $Z$ isomers as measured by the GC peak area). In the presence of glucose, however, reaction mixtures of both amino acids showed equal reactivity toward aldol condensation, because the headspace extracts of both glycine and lysine reaction mixtures contained 
about $30 \%$ hexanal and a little more than $40 \%$ 2-butyl-2-octenal after $20 \mathrm{~min}$ of reaction.

Different isomers of the aldol condensation product of $(E)-2$ hexenal, 4-ethyl-2,4,6-decatrienal, were identified in the $(E)-2$ hexenal model mixtures. Both 4-ethyl-(2E,4E,6E)-decatrienal and 4-ethyl- $(2 E, 4 Z, 6 E)$-decatrienal were tentatively identified, but correct integration of the 4-ethyl-(2E,4Z,6E)-decatrienal peak was not always possible because of the overlap with 5-butyl-2-propylpyridine. 4-Ethyl-2,4,6-decatrienal has only been reported once in the literature, as a result of the self-condensation of (E)-2-hexenal by means of diethylamine. ${ }^{17}$

Acetaldehyde and butanal are produced by the retro-aldol reaction of hydrated 2-hexenal (that is, 3-hydroxyhexanal). Because acetaldehyde is difficult to detect because of its high reactivity and low molecular weight, only trace amounts were found in the lysine/(E)-2-hexenal/glucose model system. Butanal, on the other hand, was detected in all (E)-2-hexenal model reactions, albeit in low amounts ranging from 0.02 to $1.8 \%$. Surprisingly, large amounts of butanal were present as its diethyl acetal, 1,1-diethoxybutane, which dominated in the headspace of the amino acid/(E)-2-hexenal mixtures heated for $120 \mathrm{~min}$ (38.3 and $45.7 \%$ for the lysine and glycine model systems, respectively). This compound can result from the nucleophilic addition of ethanol across butanal. Ethanol itself was detected, particularly in the glucose/(E)-2-hexenal model reactions. These model systems also contained considerable amounts of 1,1diethoxybutane, in addition to 1-ethoxy-1-butene. The latter results from the elimination of ethanol from 1,1-diethoxybutane, because it is less plausible that it is formed from the addition of ethanol to butanal followed by dehydration. Additionally, butanal is subjected to aldol condensation reactions, resulting in the formation of, on one hand, 2-ethyl-2-butenal $(0.3-6.3 \%)$ from butanal and acetaldehyde and, on the other hand, 2-ethyl-2hexenal $(0.9-31.8 \%, E$ and $Z$ isomers together) from selfcondensation of butanal.

Upon hydration and retro-aldol reaction, $(2 E, 4 E)$-decadienal yields hexanal and 2-butenal via 5-hydroxy-2-decenal and 2-octenal and acetaldehyde via 3-hydroxy-4-decenal (Table 2). Correspondingly, 2-octenal itself yields hexanal and acetaldehyde upon hydration and retro-aldolization. All of these aldehydes were present in the headspace of heated $(2 E, 4 E)$-decadienal model systems. It must be noted that the aldehydes mentioned can also be formed from $(2 E, 4 E)$-decadienal by means of autoxidation, which will in part account for their presence as well. ${ }^{18}$ Substantial amounts of dodecadienal were discovered in all of the model systems analyzed. The formation of dodecadienal in these model systems can be explained by aldol reactions of acetaldehyde with 2-decenal, resulting in 2,4-dodecadienal, or with 4-decenal, resulting in 2,6-dodecadienal. On the basis of the mass spectrum and the higher amounts of 4-decenal detected as compared to 2-decenal, this compound was tentatively identified as 2,6-dodecadienal.

Apparently, a large part of the volatiles identified can be explained by means of aldol-type reactions occurring among the carbonyl compounds involved. The same aldol-type reactions have been identified as the predominant mechanisms responsible for the formation of brown-colored high-molecular-weight polycondensation products. ${ }^{10}$ The larger part of the compounds that remain unidentified are compounds of intermediate molecular weight and, on the basis of the mass spectrum, are assumed to be aldol products of the many carbonyl compounds involved.

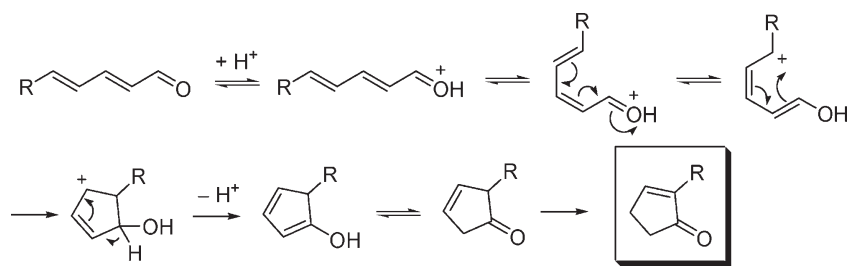

Figure 1. Formation of 2-alkyl-2-cyclopenten-1-one from the corresponding alkadienal.

Considerable amounts of hexanal were also found in $(E)-2$ hexenal model systems, especially in the (E)-2-hexenal/glucose models. According to Rizzi, ${ }^{19}$ the reaction of an $\alpha, \beta$-unsaturated carbonyl compound with an amino acid can result in the formation of the reduced carbonyl compound, following a Strecker-type degradation. In this reaction, imine formation is followed by decarboxylation and subsequent formation of the Strecker aldehyde and 1-hexenylamine. By means of isomerization to the corresponding imine and hydrolysis, 1-hexenylamine is converted into hexanal. Detection of considerable amounts of hexanal in $(E)$-2-hexenal model systems clearly demonstrates the occurrence of this reaction, which has been hypothesized but rarely observed and only for compounds with an aromatic substituent. ${ }^{19}$

A considerable part of hexanal was oxidized to hexanoic acid, a compound that is not very sensitive to headspace SPME extraction; detection thus indicates the presence of considerable amounts of acid. It was an important constituent of the headspace of lysine/hexanal model mixtures $(12.0-15.9 \%)$ and, to a lesser extent, of the glycine/hexanal/glucose reaction mixture (8.4\%) as well.

In addition, some methyl ketones, which are important volatiles in the flavor deterioration of dairy products, were detected (2-butanone, 2-pentanone, and 2-hexanone). Macku and Shibamoto ${ }^{8}$ previously showed in a model mixture of corn oil and glycine that secondary reactions occurred between glycine and the volatile aldehydes formed from the heated corn oil. A positive linear correlation was found between methyl ketone formation and the amount of glycine added. The formation of methyl ketones can be partly explained by the principle of chain elongation, first described by Yaylayan and Keyhani ${ }^{20}$ in a glucose/alanine Maillard model system. Following this mechanism, an aldehyde is converted into the corresponding methyl ketone by reaction with glycine. Thus, for example, 2-pentanone can be formed from the reaction of butanal with glycine, 2-hexanone from pentanal and glycine, and 2-heptanone from hexanal and glycine. Because 2-heptanone was, however, only detected in the glycine/(2E,4E)-decadienal model systems, the mechanism of chain elongation is probably of minor importance in these model systems.

Intramolecular cyclization of $(2 E, 4 E)$-decadienal yields 2-pentyl-2-cyclopenten-1-one (up to $2.3 \%$ ), according to the mechanism shown in Figure 1. In this hypothesized mechanism, the alkadienal is protonated, inducing ring closure after $E$ to $Z$ isomerization. Subsequently, rearrangement of the double bonds leads to the corresponding 2-alkyl-2-cyclopenten-1-one. The intermediacy of 2-alkyl-3-cyclopenten-1-one and its transformation to the thermodynamically more stable 2-alkyl-2-cyclopenten-1-one has been described before. ${ }^{21}$ Correspondingly, 2-methyl2-cyclopenten-1-one was detected in some of the (E)-2-hexenal model systems (up to $0.5 \%$ ). In this case, dehydrogenation of 


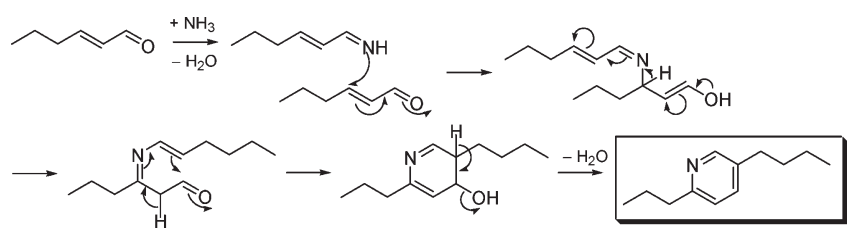

Figure 2. Formation of 5-butyl-2-propylpyridine from (E)-2-hexenal and ammonia.

2-hexenal to 2,4-hexadienal is required in a first step. 2-Pentyl-2cyclopenten-1-one is one of the volatile constituents detected in used frying oils, ${ }^{22}$ as were most of the compounds identified in Tables 1 and 2. In addition, intramolecular cyclization of $(2 E, 4 E)$-decadienal toward a six-membered ring results in the formation of butylbenzene, which was detected in the headspace fraction of all $(2 E, 4 E)$-decadienal model reaction mixtures.

Oxidation of $(E)$-2-hexenal in the allylic position followed by cyclization results in the formation of 2-ethylfuran, the main oxygen-containing heterocyclic compound among the $(E)-2$ hexenal headspace constituents. According to the same reaction mechanism, 2-butylfuran is formed from 2-octenal, 2-pentylfuran from 2-nonenal, 2-hexylfuran from 2-decenal, 5-ethyl-2 $(5 H)$ furanone from hexanoic acid, and 2-hex-1-enylfuran from 2,4decadienal. Especially in the $(2 E, 4 E)$-decadienal model systems, these 2-alkylfurans were quite important headspace constituents and have also been identified before in 2,4-decadienal model mixtures. ${ }^{23}$ A detailed study of the formation of 2-alkylfurans in model reactions of lipid-derived $\alpha, \beta$-unsaturated aldehydes with amino acids will be reported elsewhere.

Only one nitrogen-containing aromatic volatile compound was identified in the headspace of the (E)-2-hexenal model reactions, in particular 5-butyl-2-propylpyridine. A mechanism of formation of this compound, resulting from the condensation of two molecules of $(E)$-2-hexenal with ammonia, is proposed in Figure 2. In this hypothesized reaction mechanism, the imine formed from (E)-2-hexenal with ammonia performs a Michaeltype addition reaction toward a second molecule of (E)-2hexenal. After rearrangement of the double bonds, cyclization occurs, which yields 5-butyl-2-propylpyridine after elimination of water. The release of ammonia from amino acids upon heating has been described. Model studies have shown that especially glutamine released considerable amounts of ammonia upon moderate heating $\left(11{ }^{\circ} \mathrm{C}\right)$, while glycine and lysine yielded low amounts of ammonia upon more elevated heating at $180^{\circ} \mathrm{C}$ for $2 \mathrm{~h}$ in aqueous solution ( $\mathrm{pH} 8) .^{24}$ In our model experiments, 5-butyl-2-propylpyridine was only detected after prolonged heating ( $120 \mathrm{~min}, 125^{\circ} \mathrm{C}$, and dry). Its formation might still increase with stronger heating conditions.

2-Pentylpyridine was detected in the headspace of most $(2 E, 4 E)$-decadienal model systems in the absence of glucose. This compound was also detected after thermal degradation of $(2 E, 4 E)$-decadienal/amino acid polycondensation products, in a relatively large quantity compared to the other volatile azaheterocycles detected. ${ }^{10}$ This very potent odorant is responsible for grassy aroma defects in soybean products. ${ }^{11}$ Its formation results from the reaction of $(2 E, 4 E)$-decadienal with either free ammonia (released from the amino acids) or the $\alpha$-amino group bound in amino acids. ${ }^{25}$

Besides the compounds described above, several volatile alkanes, alkenes, and alcohols were detected in the headspace of the amino acid/carbonyl compound samples. The release of these volatiles was favored at the final stages of the reaction. They probably result from enhanced degradation and recombination of fragments of the lipid-derived aldehydes. Among these, 4- and 5 -undecene were repeatedly found in hexanal model systems. Also benzaldehyde needs to be mentioned as a known autoxidation product of $(2 E, 4 E)$-decadienal. ${ }^{26}$

When these lipid oxidation aldehydes [hexanal, $(2 E)$-hexenal, and $(2 E, 4 E)$-decadienal] were heated alone, no browning occurred and no significant degradation took place. The results presented thus demonstrate that, although few reaction products were found resulting from the actual condensation of an amino acid with a lipid oxidation aldehyde, the amino acid plays a very significant role in catalyzing the degradation and further reaction of these carbonyl compounds. It seems that aldol condensation reactions of lipid oxidation aldehydes catalyzed by an amino acid are very important in the overall formation of aroma volatiles in such reaction mixtures. Thus, in addition to the degradation of amino acids induced by lipid oxidation products, which has been reported before by Hidalgo and co-workers, ${ }^{3,4}$ amino-acid-induced degradations and further reactions of lipid oxidation products may be of considerable importance in thermally processed foods as well. In addition, most of the volatiles identified in this study have been reported as volatile constituents of thermally processed lipidrich food products, ${ }^{21,29,32}$ indicating that the mechanisms explained play a role in the formation of food volatiles.

The amino-acid-induced degradation of lipid oxidation products is comparable to the amino-acid-induced carbohydrate degradation as commonly described in Maillard-type reactions. The heating conditions applied $\left(125^{\circ} \mathrm{C}\right.$ and $\left.20 \mathrm{~min}\right)$ are also not severe enough to induce caramelization or (detectable) formation of furans upon heating of glucose alone. At these heating conditions, also the extent of the Maillard reaction in the corresponding glycine/glucose and lysine/glucose model reactions was rather limited. Typical Maillard flavor compounds, in particular, 2-methylfuran, 2,5-dimethylfuran, furfural, and 2-acetylfuran, were only detected after prolonged heating for $120 \mathrm{~min}$ (data not shown). No nitrogen-containing compounds were detected under these conditions. In comparison to this, a higher degree of browning and volatile formation was observed in the model systems containing lipid oxidation products, thus illustrating their potential importance in real food systems, which, of course, consist of a complex mixture of several compounds.

Comparison of the amino acid/lipid oxidation product model systems in the absence and presence of glucose reveals differences mainly in the relative composition of the headspace extracts. Specific compounds indicative of an interaction between the three components in these amino acid/aldehyde/glucose model reactions were not found. Again, especially aldol products of the carbonyl compounds involved were predominant in the headspace extract, indicating the importance of these reactions in thermally processed foods.

\section{AUTHOR INFORMATION}

\section{Corresponding Author}

*Telephone: +32-9-264-59-51. Fax: +32-9-264-62-43. E-mail: norbert.dekimpe@ugent.be.

\section{Funding Sources}

The authors are indebted to the Research Foundation-Flanders (Belgium) (FWO-Vlaanderen) for a postdoctoral fellowship to An Adams. 


\section{REFERENCES}

(1) Whitfield, F. B. Volatiles from interactions of Maillard reactions and lipids. Crit. Rev. Food Sci. Nutr. 1992, 31, 1-58.

(2) Zamora, R.; Hidalgo, F. J. Coordinate contribution of lipid oxidation and Maillard reaction to the nonenzymatic food browning. Crit. Rev. Food Sci. Nutr. 2005, 45, 49-59.

(3) Hidalgo, F. J.; Zamora, R. Strecker-type degradation produced by the lipid oxidation products 4,5-epoxy-2-alkenals. J. Agric. Food Chem. 2004, 52, 7126-7131.

(4) Hidalgo, F. J.; Gallardo, E.; Zamora, R. Strecker-type degradation of phenylalanine by 4-hydroxy-2-nonenal in model systems. J. Agric. Food Chem. 2005, 53, 10254-10259.

(5) Lien, Y. C.; Nawar, W. W. Thermal interaction of amino acids and triglycerides. Valine and tricaproin. J. Food Sci. 1974, 39, 917-919.

(6) Breitbart, D.; Nawar, W. W. Thermal interaction of lysine and triglycerides. J. Agric. Food Chem. 1981, 29, 1194-1196.

(7) Henderson, S. K.; Nawar, W. W. Thermal interaction of linoleic acid and its esters with valine. J. Am. Oil Chem. Soc. 1981, 58, 632-635.

(8) Macku, C.; Shibamoto, T. Headspace volatile compounds formed from heated corn oil and corn oil with glycine. J. Agric. Food Chem. 1991, 39, 1265-1269.

(9) Wang, Z.; Wu, Q. H.; Wu, C.-M. Effect of sucrose on the volatile compounds produced from heated glycine and soybean oil. Food Sci. Technol. Res. 1999, 5, 393-397.

(10) Adams, A.; Kitryte, V.; Venskutonis, R.; De Kimpe, N. Formation and characterization of melanoidin-like polycondensation products from amino acids and lipid oxidation products. Food Chem. 2009, 115, 904-911.

(11) Belitz, H.-D.; Grosch, W.; Schieberle, P. Food Chemistry, 3rd revised ed.; Springer-Verlag: Heidelberg, Germany, 2004.

(12) Robert, F.; Héritier, J.; Quiquerez, J.; Simian, H.; Blank, I. Synthesis and sensorial properties of 2-alkylalk-2-enals and 3-(acetylthio)-2-alkyl alkanals. J. Agric. Food Chem. 2004, 52, 3525-3529.

(13) Pokorny, J.; Janitz, W.; Viden, I.; Velisek, J.; Valentova, H.; Davidek, J. Reaction of oxidized lipids with protein: Part 14. Aldolization reactions of lower alkanes in the presence of nonlipidic substances. Nahrung 1987, 1, 63-70.

(14) List, B.; Lerner, R. A.; Barbas, C. F. Proline-catalyzed direct asymmetric aldol reactions. J. Am. Oil Chem. Soc. 2000, 122, 2395-2396.

(15) Cordova, A.; Zou, W.; Dziedzic, P.; Ibrahem, I.; Reyes, E.; Xu, Y. Direct asymmetric intermolecular aldol reactions catalyzed by amino acids and small peptides. Chem.-Eur. J. 2006, 12, 5385-5397.

(16) Lombardo, M.; Easwar, S.; Pasi, F.; Trombini, C.; Dhavale, D. D. Protonated arginine and lysine as catalysts for the direct asymmetric aldol reaction in ionic liquids. Tetrahedron 2008, 64, 92039207.

(17) Tadahiko, K.; Akikazu, H.; Yuzo, I.; Minoru, O. Leaf alcohol. XVIII. Condensation of leaf aldehyde by means of diethylamine. Agric. Biol. Chem. 1969, 33, 409-413.

(18) Josephson, D. B.; Lindsay, R. C. Retro-aldol related degradations of 2,4-decadienal in the development of staling flavors in fried foods. J. Food Sci. 1989, 52, 1186-1190.

(19) Rizzi, G. The Strecker degradation of amino acids: Newer avenues for flavor formation. Food Rev. Int. 2008, 24, 416-435.

(20) Yaylayan, V.; Keyhani, A. Origin of 2,3-pentanedione and 2,3butanedione in glucose/L-alanine Maillard model systems. J. Agric. Food Chem. 1999, 47, 3280-3284.

(21) Elia, G. R.; Childs, R. F.; Shaw, G. S. Thermal cyclizations of protonated polyunsaturated aldehydes. Can. J. Chem. 1992, 70, 20652069.

(22) Takeoka, G.; Perrino, C., Jr.; Buttery, R. Volatile constituents of used frying oils. J. Agric. Food Chem. 1996, 44, 654-660.

(23) Zhang, Y.; Ho, C.-T. Volatile compounds formed from thermal interaction of 2,4-decadienal with cysteine and glutathione. J. Agric. Food Chem. 1989, 37, 1016-1020.

(24) Sohn, M.; Ho, C.-T. Ammonia generation during thermal degradation of amino acids. J. Agric. Food Chem. 1995, 43, 3001-3003.
(25) Kim, Y.-S.; Hartman, T. G.; Ho, C.-T. Formation of 2-pentylpyridine from the thermal interaction of amino acids and 2,4-decadienal. J. Agric. Food Chem. 1996, 44, 3906-3908.

(26) Bruechert, L. J.; Zhang, Y.; Huang, T. C.; Hartman, T. G.; Rosen, R. T.; Ho, C.-T. Contribution of lipids to volatile generation in extruded corn-based model systems. J. Food Sci. 1988, 53, 1444-1447.

(27) Schnermann, P.; Schieberle, P. Evaluation of key odorants in milk chocolate and cocoa mass by aroma extract dilution analysis. J. Agric. Food Chem. 1997, 45, 867-872.

(28) Fuhrmann, E.; Grosch, W. Character impact odorants of the apple cultivars Elstar and Cox orange. Nahrung 2002, 46, 187-193.

(29) Elmore, J. S.; Mottram, D. S.; Enser, M.; Wood, J. D. The effects of diet and breed on the volatile compounds of cooked lamb. Meat Sci. 2000, 55, 149-159.

(30) Adams, R. P. Identification of Essential Oil Components by Gas Chromatography/Mass Spectrometry, 4th ed.; Allured Publishing Corporation: Carol Stream, IL, 2006.

(31) Pino, J. A.; Mesa, J.; Munoz, Y.; Marti, M. P.; Marbot, R. Volatile components from mango (Mangifera indica L.) cultivars. J. Agric. Food Chem. 2005, 53, 2213-2223.

(32) Hierro, E.; de la Hoz, L.; Ordóñez, J. A. Headspace volatile compounds from salted and occasionally smoked dried meats (cecinas) as affected by animal species. Food Chem. 2004, 85, 649-657.

(33) Machiels, D.; Van Ruth, S. M.; Posthumus, M. A.; Istasse, L. Gas chromatography-olfactometry analysis of the volatile compounds of two commercial Irish beef meats. Talanta 2003, 60, 755-764.

(34) Triqui, R.; Reineccius, G. A. Changes in flavor profiles with ripening of anchovy (Engraulis encrasicholus). J. Agric. Food Chem. 1995, 43, 1883-1889.

(35) Bredie, W. L. P.; Mottram, D. S.; Guy, R. C. E. Effect of temperature and $\mathrm{pH}$ on the generation of flavour volatiles in extrusion cooking of wheat flour. J. Agric. Food Chem. 2002, 50, 1118-1125.

(36) Adams, A.; Abbaspour Tehrani, K.; Kersiene, M.; Venskutonis, R.; De Kimpe, N. Characterization of model melanoidins by the thermal degradation profile. J. Agric. Food Chem. 2003, 51, 4338-4343. 